\title{
ANÁLISE DA INJEÇÃO DE CO2 EM RESERVATÓRIOS DE ÓLEOS LEVES COM CARACTERÍSTICAS DO NORDESTE BRASILEIRO.
}

\author{
C. S. do N. GARCIA ${ }^{1}$, J. L M. BARILLAS ${ }^{2}$ \\ ${ }^{1}$ Universidade Federal do Rio Grande do Norte, Departamento de Engenharia de Petróleo \\ ${ }^{2}$ Universidade Federal do Rio Grande do Norte, Departamento de Engenharia de Petróleo

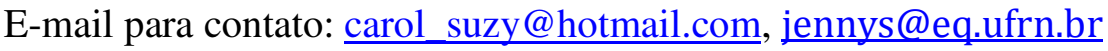

RESUMO - Indústrias petrolíferas investem constantemente em busca de novas tecnologias que aumentem o volume de hidrocarbonetos recuperados, buscando atingir fatores de recuperação de até $70 \%$. O processo de drenagem gravitacional assistida por gás (GAGD) foi desenvolvido visando aumentar o fator de recuperação desse óleo, esse método consiste em injetar gás $(\mathrm{CO} 2$, metano, etc) no topo de um reservatório, aproveitando a segregação gravitacional natural dos fluidos, até um poço produtor horizontal que está na base do reservatório. Para estudar este processo foi elaborado um modelo físico que representa um reservatório homogêneo de óleo leve com características do Nordeste brasileiro. E assim, por meio de um simulador composicional alguns parâmetros operacionais foram analisados, o processo foi simulado no programa comercial GEM da CMG (Computer Modelling Group). Os parâmetros analisados foram vazão de injeção e tipo de fluido injetado. Os resultados mostraram que o parâmetro de maior influência na fração de óleo recuperada foi a vazão de injeção, apresentando um incremento de mais de $40 \%$ no fator de recuperação.

\section{INTRODUÇÃO}

O petróleo é atualmente fonte energética em diversas áreas no mundo, devido a isso, pesquisas de novas jazidas são realizadas a fim de se suprir essa dependência que a população mundial vive dos subprodutos do petróleo.

As reservas de petróleo possuem nas suas descobertas, certa quantidade de energia denominada de energia primária. Esta pode ser capaz de realizar a produção dos poços de petróleo sem a necessidade de uma energia adicional. Ao iniciar a produção essa energia vai se esgotando por conta da descompressão dos fluidos e das resistências encontradas pelo mesmo ao fluir em direção ao poço produtor. Estas resistências são devidas, ou associadas, às forças capilares e viscosas presentes no meio poroso. A dissipação da energia primária implica na redução da produtividade dos poços por conta da diminuição da pressão na vida do reservatório.

Isto leva a necessidade da utilização de métodos de recuperação suplementares a fim de se elevar o fator de recuperação do petróleo. Empresas no Brasil e no mundo buscam constantemente desenvolver novas tecnologias e processos com um equilibrado custo-benefício. 
O processo de drenagem gravitacional assistida por gás (GAGD) foi desenvolvido visando aumentar o fator de recuperação desse óleo. Esse método consiste em injetar gás (CO2, metano, etano, propano, nitrogênio, etc) no topo de um reservatório, aproveitando a segregação gravitacional natural dos fluidos, até um poço produtor horizontal que está na base do reservatório.

O aumento no fator de recuperação devido a métodos de recuperação com injeção de gás é baixo, já que estes métodos não conseguiam superar o efeito negativo gerado pela segregação gravitacional natural dos fluidos do reservatório e dos injetados. Entretanto, o GAGD aproveita a segregação natural dos fluidos para maximizar a produção de óleo, onde o gás é injetado pelo topo do reservatório por meio de poços injetores verticais ou um poço injetor horizontal. Assim, uma frente de gás se cria no topo, essa frente vai se expandindo e deslocando o óleo para baixo até um poço produtor horizontal que está na base do reservatório.

Para estudar este processo foi elaborado um modelo físico que representa um reservatório homogêneo de óleo leve, com características do Nordeste brasileiro, utilizando propriedades físicas e fluidodinâmicas reais e um modelo de fluido multicomponente. E assim, por meio de um simulador composicional alguns parâmetros operacionais foram analisados, o processo foi simulado no programa comercial GEM da CMG (Computer Modelling Group) em 20 anos de projeto. Foi realizado o estudo de alguns parâmetros operacionais na recuperação de óleo.

\section{MODELAGEM DO PROCESSO}

A elaboração do modelo final do reservatório foi dividida em duas etapas, primeiramente o modelo de fluido foi construído no Winprop e em seguida importado para o Builder onde foi realizada a construção do modelo de malhas do reservatório e a perfuração dos poços.

O modelo de fluido, característico de bacia no Nordeste brasileiro foi em ajustado em sete pseudo-componentes mostrados na Tabela 1, caracterizando um óleo leve.

Tabela 1 - Composição do pseudo-componentes

\begin{tabular}{|c|c|}
\hline Componente & Fração Molar \\
\hline CO2_INJ & 0,00 \\
\hline N2 & 0,00058 \\
\hline CO2 to CH3 & 0,00035 \\
\hline IC4 to NC5 & 0,07035 \\
\hline C6 to C10 & 0,470 \\
\hline C11 to C19 & 0,131 \\
\hline C20+ & 0,323 \\
\hline
\end{tabular}

Para o desenvolvimento do presente trabalho foi utilizado um modelo de reservatório homogêneo baseado em modelo de uma bacia do Nordeste brasileiro com forma retangular. A 
Tabela 2 apresenta as características desse modelo físico, suas dimensões e os dados de propriedades do reservatório adotado.

Tabela 2 - Características do reservatório

\begin{tabular}{|l|c|}
\hline \multicolumn{1}{|c|}{ Característica } & Valor \\
\hline Número total de blocos & 6720 \\
\hline Dimensão em x (m) & 100 \\
\hline Dimensão em y $(\mathrm{m})$ & 300 \\
\hline Dimensão em z (m) & 30 \\
\hline Número de blocos em i (m) & 21 \\
\hline Número de blocos em j (m) & 20 \\
\hline Número de blocos em k $(\mathrm{m})$ & 16 \\
\hline Saturação inicial da água conata, Swc & 0,28 \\
\hline Volume Original de óleo $\left(\mathrm{m}^{3} \mathrm{std}\right)$ & $1,1967 \times 10^{5}$ \\
\hline Volume Original de água $\left(\mathrm{m}^{3} \mathrm{std}\right)$ & $1,31174 \times 10^{5}$ \\
\hline Espessura da zona de óleo $(\mathrm{m})$ & 20 \\
\hline Profundidade do reservatório $(\mathrm{m})$ & 489 \\
\hline Porosidade $(\%)$ & 28 \\
\hline Permeabilidade Horizontal, Kh $(\mathrm{mD})$ & 630 \\
\hline Permeabilidade Vertical, Kv $(\mathrm{mD})$ & 63 \\
\hline Compressibilidade da rocha $(1 / \mathrm{kPa})$ & $2,0305 \times 10^{-6}$ \\
\hline
\end{tabular}

Após a inserção dos dados de fluido e do modelo físico do reservatório, foi realizada a construção das malhas e a perfuração dos poços. As dimensões do reservatório são de 100 metros de largura, 300 metros de comprimento e 30 metros de espessura, sendo 20 metros da zona de óleo e 10 metros da zona de água. A perfuração foi feita na zona de óleo, o poço produtor horizontal foi perfurado a uma distância considerável zona da água e o poço injetor horizontal foi perfurado duas camadas abaixo do topo do reservatório, na parte superior da zona de óleo afim de se máximar os efeitos da drenagem gravitacional dos fluidos ate o poço produtor localizado na parte inferior.

As dimensões e direções do modelo numa visão em três dimensões, criado já no Builder, ilustram-se na Figura 1. 


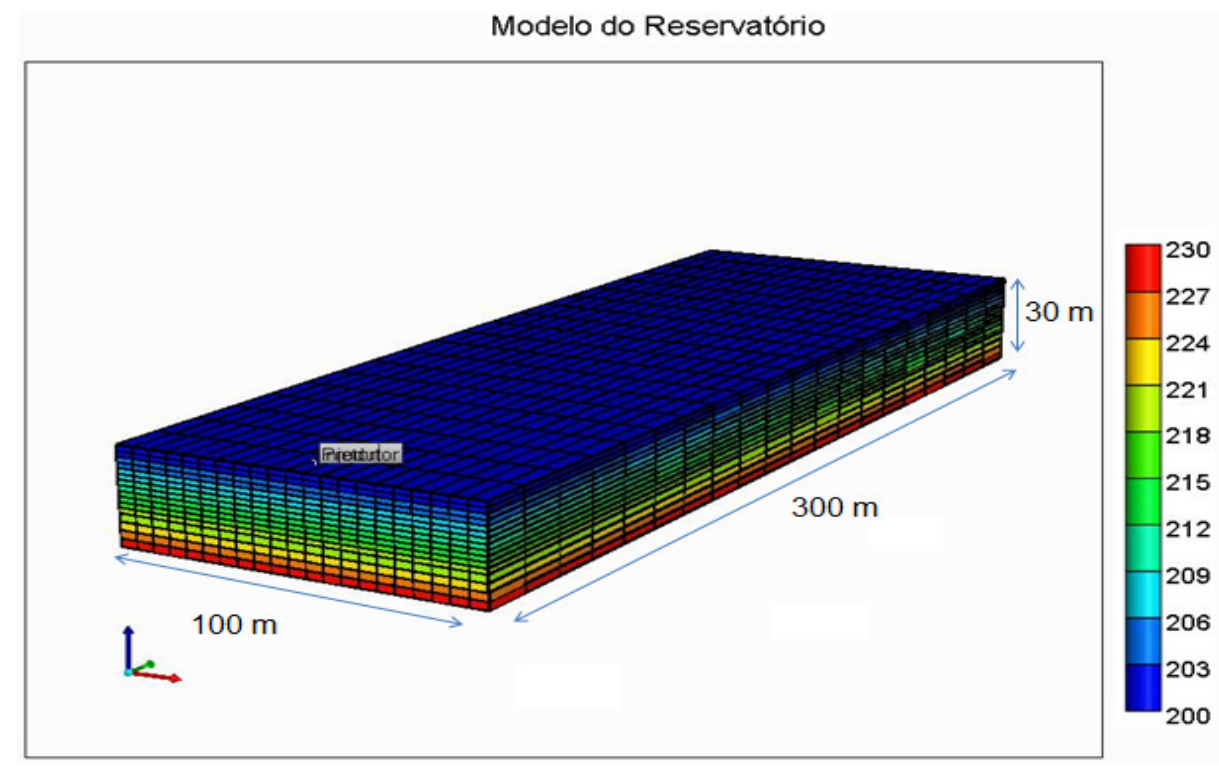

Figura 1- Dimensões da malha retangular (Vista 3D)

Após a completação foi definido uma vazão de injeção para o $\mathrm{CO} 2 \mathrm{de} 100 \mathrm{~m} / \mathrm{dia}$, configuração modelo base ilustrado na

Figura 2, para uma análise inicial do processo de recuperação de hidrocarbonetos pelo método GAGD. O projeto estudado tem uma duração de 20 anos.

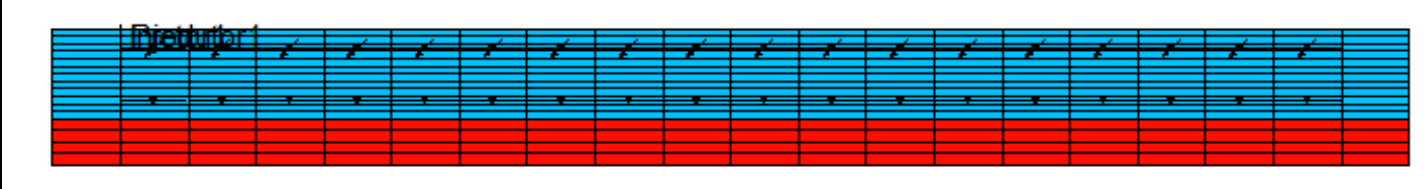

Figura 2 - Configuração do Modelo base

A partir da criação do modelo base alguns parâmetros operacionais foram modificados a fim de se avaliar a influência dos mesmos, são eles:

- Vazão de injeção do CO2 (100, 500, 3000, 20000, 50000 m³/dia);

- O tipo de fluido injetado (água e CO2); 


\section{RESULTADOS E DISCUSSÕES}

Simulações foram realizadas injetando-se $\mathrm{CO} 2$, a fim de se estudar o comportamento do GAGD no modelo de reservatório adotado, a partir do estudo dos parâmetros operacionais, buscando sempre a otimização do processo.

Inicialmente foi feita uma análise comparativa entre o modelo base do GAGD com injeção de $\mathrm{CO} 2$ e o modelo com a mesma configuração, mas sem injeção de gás (recuperação primária). Na Figura 3, está ilustrado o fator de recuperação da recuperação primária e do modelo com injeção de $\mathrm{CO} 2$, claramente observa-se que a quantidade de óleo recuperada para o modelo com injeção de gás teve um acréscimo de $21,12 \%$ em relação à recuperação do modelo sem injeção. Este acréscimo se deve ao fato de que o gás injetado age no deslocamento do óleo e após o breaktrought o mecanismo de deslocamento dá lugar ao mecanismo de gravidade, onde a segregação vertical começa a ganhar força drenando os fluidos do topo para o fundo até poço horizontal para estes serem produzidos, sendo, portanto, mais eficiente que o modelo sem injeção.

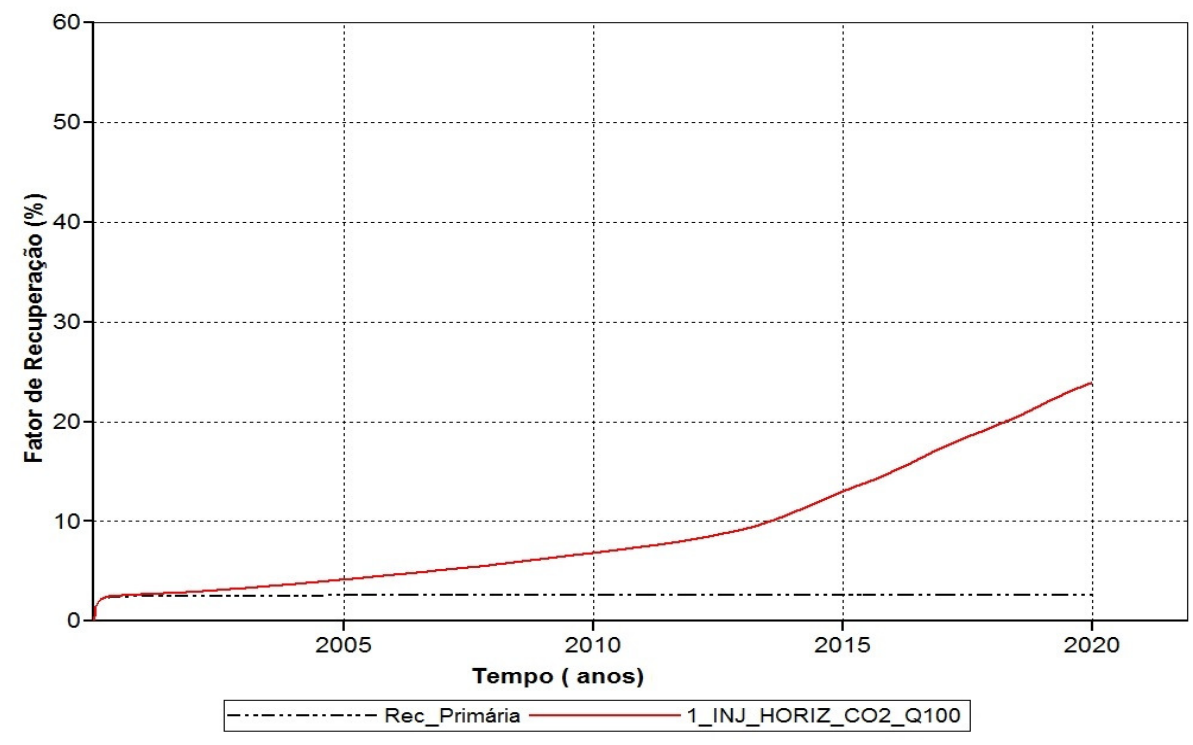

Figura 3 - Gráfico comparativo do fator de recuperação do modelo base e o modelo sem injeção

Novas simulações foram feitas na procura dos melhores cenários do processo GAGD para obter o maior fator de recuperação de óleo possível e a otimização do processo, visando comparar a eficiência da injeção de $\mathrm{CO} 2$ com a injeção de água e analisar o efeito do aumento da vazão de injeção. A vazão de injeção da água foi variando de 100, 150, 200 e $3000 \mathrm{~m}^{3} /$ dia e a vazão de $\mathrm{CO} 2$ foi de 100, 500, 3000, 20000 e 50000 m²dia. A Figura 4 mostra que mesmo para elevadas vazões de água injetada o fator de recuperação não tem um acréscimo considerado, já para uma elevada vazão de $\mathrm{CO} 2$ é notório o aumento na recuperação, sendo a injeção com $500 \mathrm{~m}^{3} / \mathrm{dia}$ de CO2 bem mais viável que a injeção de 3000 m²/dia de água. 


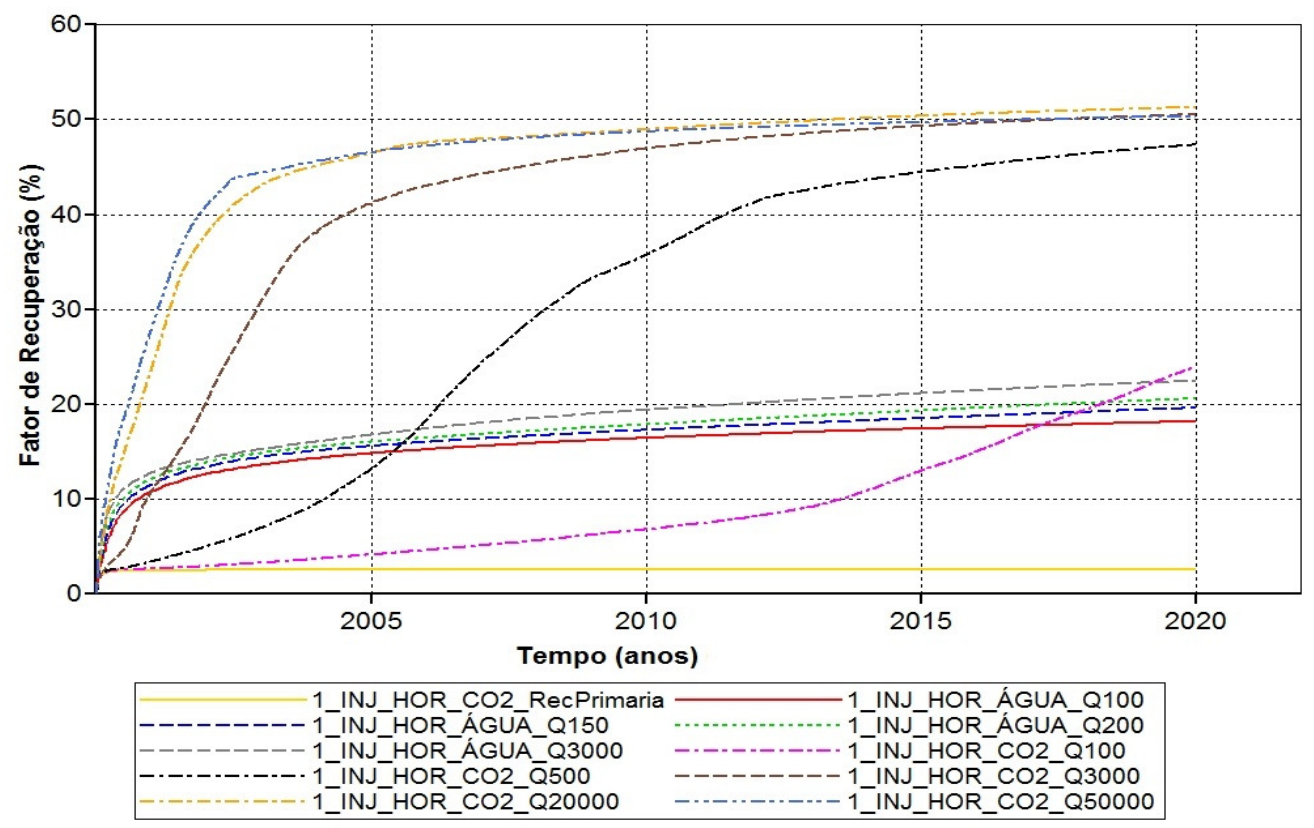

Figura 4 - Gráfico comparativo entre injeção de água e CO2

Para entender fisicamente a influência do tipo de fluido injetado foram gerados figuras em 3D, a fim de se observar como a fração molar da parte mais pesada do óleo no reservatório se comporta quando água ou óleo é injetado, Figura 5 e Figura 6.

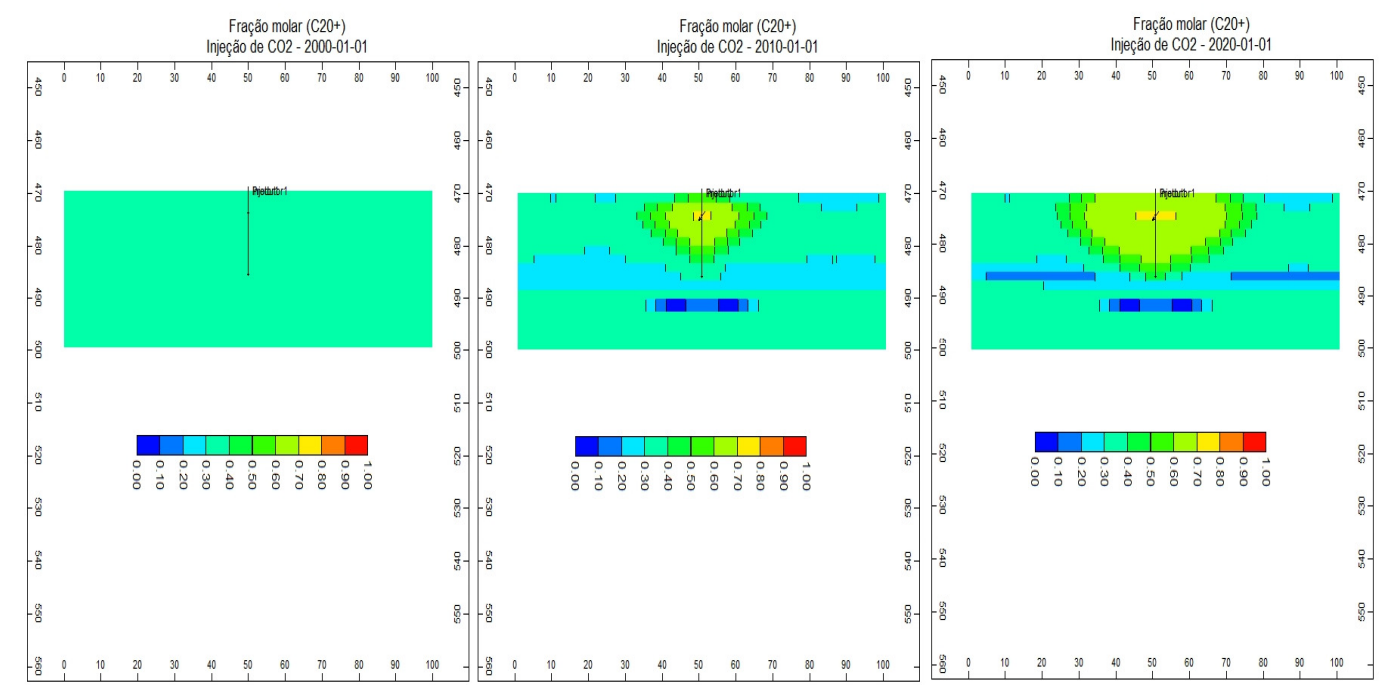

Figura 5 - Fração Molar do C20+ com injeção de CO2 a uma vazão de 3000m³/dia 


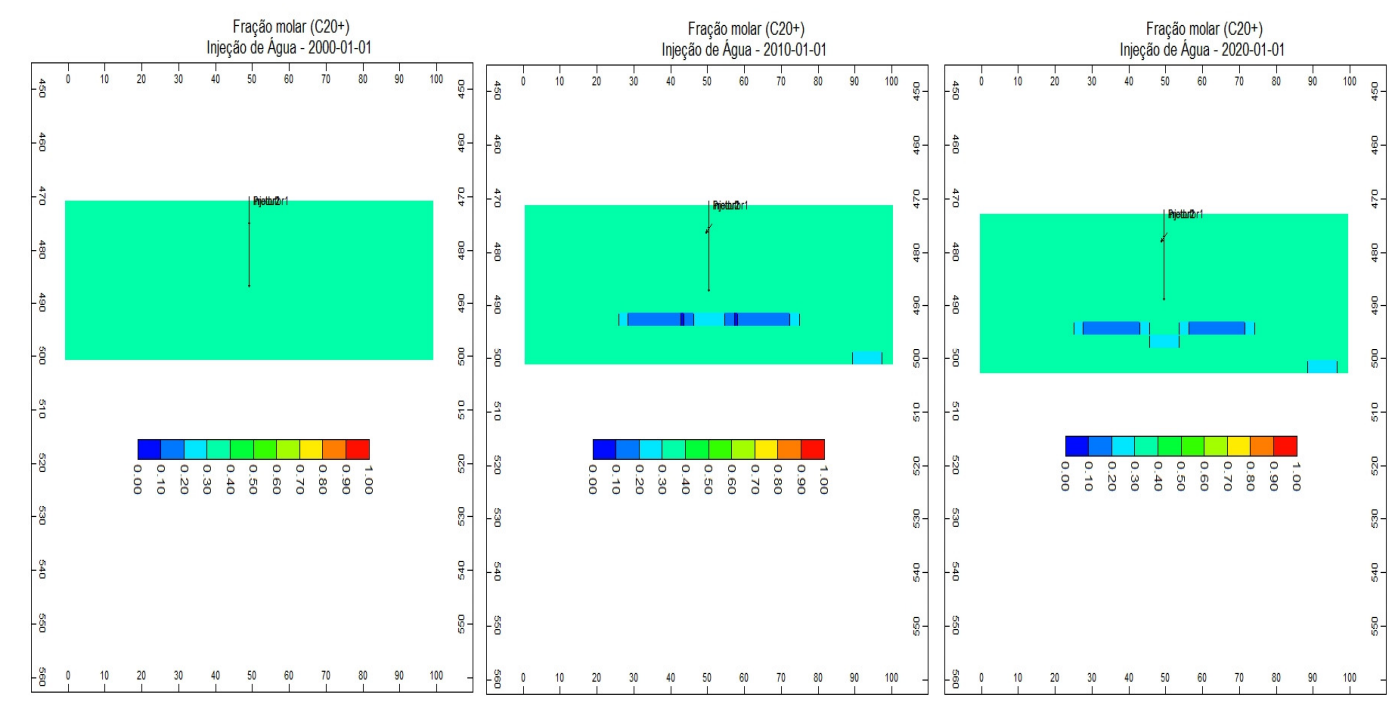

Figura 6 - Fração Molar do C20+ com injeção de Água a uma vazão de 3000m²/dia

Claramente observa-se que a quantidade da fração do C20+ vai aumentando com injeção de $\mathrm{CO} 2$ à medida que o óleo vai sendo produzido, o que não ocorre na injeção de água, isto ocorre devido ao fato da produção ser bem superior quando usado $\mathrm{CO} 2$, pois a recuperação elevada vai produzindo as frações mais leves e óleo remanescente no reservatório apresenta esse elevador teor. Esse aumento não ocorre quando a água é injetada, pois a recuperação de hidrocarbonetos não se mostrou muito eficiente, produzindo assim, apenas uma parte das frações mais leves.

Outra análise feita ainda sobre a Figura 4 é com relação à vazão de injeção, onde é possível observar que para os primeiros anos de projeto é perceptível que quanto maior é a vazão de injeção maior é volume de hidrocarbonetos recuperados, entretanto é notório que não há uma diferença significativa para a vazão de 20000 e a de $50000 \mathrm{~m}^{3} /$ dia. Portanto, a vazão de 50000 $\mathrm{m}^{3} /$ dia foi excluída da escolha do melhor cenário, já que, de acordo com os gráficos do fator de recuperação percebe-se que o reservatório atingiu um limite de produção e assim essa vazão mais alta não se torna viável por não apresentar um aumento no volume recuperado e possivelmente apresenta um maior custo.

Portanto, a vazão de $20000 \mathrm{~m}^{3} /$ dia foi escolhida como o melhor cenário levando em conta o fator de recuperação para os primeiros anos de projeto, entretanto não se pode desconsiderar o fato de que a vazão de $3000 \mathrm{~m} 3 /$ dia também apresentou uma boa recuperação, isto se justifica pelo fato de que o GAGD é um processo de drenagem gravitacional e assim após a erupção do gás injetado a produção passa a ser dominada pela força gravitacional mantendo a recuperação elevada mesmo com uma vazão reduzida. 


\section{CONCLUSÕES}

Em geral, o modelo estudado do GAGD apresentou um incremento na recuperação em torno de $50 \%$ em relação à recuperação primária do reservatório.

Observou-se que o $\mathrm{CO} 2$ tem uma eficiência de recuperação bem superior quando comparado com a injeção de água, com um acréscimo de mais de $20 \%$ no fator de recuperação para o caso com injeção de $\mathrm{CO} 2$.

A vazão de injeção do $\mathrm{CO} 2$ apresentou-se como parâmetro principal para a otimização do processo GAGD. Verificou-se que para maiores vazões de injeção há uma maior recuperação de óleo e também foi possível observar que após a erupção do $\mathrm{CO} 2$, a força gravitacional pareceu ser mais dominante sobre a força viscosa.

\section{AGRADECIMENTOS}

A CMG (Computer Modelling Group) pela licença concedida a UFRN e a Petrobras pelo apoio financeiro por meio de bolsas de estudo.

\section{REFERÊNCIAS}

BARILLAS, Jennys Lourdes Meneses - Estudo do processo de drenagem gravitacional de óleo com injeção contínua de vapor em poços horizontais, Natal-RN, 2005.

BAUTISTA, E. V. - Análise Paramétrica da simulação Composicional do Processo de Drenagem Gravitacional Assistida por Gás (GAGD). Dissertação de Mestrado em Ciência e Engenharia de Petróleo, Universidade Federal do Rio Grande do Norte, 2010. Natal-RN.

$>$ PINTO, T. A. - Estudo Paramétrico da Recuperação de Óleo no Processo de Drenagem Gravitacional com Injeção de CO2. Dissertação de Mestrado em Ciência e Engenharia de Petróleo, Universidade Federal do Rio Grande do Norte, 2009. Natal-RN.

$>$ ROSA, A. J.; CARVALHO, R. S.; XAVIER, J. A. D. Engenharia de Reservatórios de Petróleo. Rio de Janeiro: Interciência, 2006.

> RUIZ, C. P. A. - Estudo Comparativo da Injeção de Água Usando Poços Verticais e Horizontais. Dissertação de Mestrado em Ciência e Engenharia de Petróleo, Universidade Federal do Rio Grande do Norte, 2012. Natal-RN.

$>$ THOMAS, J. E. et al. Fundamentos da Engenharia de Petróleo. 2. ed. Rio de Janeiro: Interciência, 2001. 